CLINICAL STUDY

\title{
Phenotyping and genetic studies of 357 consecutive patients presenting with premature ovarian failure
}

\author{
Anne Bachelot ${ }^{1,2}$, Agnès Rouxel $^{1}$, Nathalie Massin ${ }^{1}$, Jérome Dulon ${ }^{1}$, Carine Courtillot $^{1}$, Christine Matuchansky ${ }^{3}$, \\ Yasmina Badachi ${ }^{4}$, Anne Fortin ${ }^{5}$, Bernard Paniel ${ }^{6}$, Fabrice Lecuru ${ }^{7}$, Marie-Aude Lefrère-Belda ${ }^{8}$, \\ Elisabeth Constancis ${ }^{9}$, Elisabeth Thibault ${ }^{10}$, Géri Meduri ${ }^{11,12}$, Anne Guiochon-Mantel ${ }^{11,12}$, Micheline Misrahi ${ }^{12,13}$, \\ Frédérique Kuttenn $^{1,2}$, Philippe Touraine ${ }^{1,2}$ on behalf of the POF-GIS Study Group \\ ${ }^{1}$ AP-HP, Department of Endocrinology and Reproductive Medicine, Centre de référence des Maladies Endocriniennes rares de la croissance, Groupe \\ Hospitalier Pitié-Salpétrière, University Pierre et Marie Curie, Paris VI, 75013 Paris, France, ${ }^{2}$ INSERM U845, 75015 Paris, France, ${ }^{3}$ AP-HP, \\ Department of Radiology, Groupe Hospitalier Necker-Enfants Malades, 75015 Paris, France, AP-HP, Departments of ${ }^{4}$ Radiology and ${ }^{5}$ Obstetrics and \\ Gynecology, Groupe Hospitalier Pitié-Salpétrière, 75013 Paris, France, ${ }^{6}$ AP-HP, Department of Gynecological Surgery, Centre Hospitalier Intercommunal \\ de Créteil, 94010 Créteil, France, AP-HP, Departments of ${ }^{7}$ Gynecological Surgery and ${ }^{8}$ Pathology, Hôspital Européen Georges Pompidou, 75015 Paris, \\ France, ${ }^{9}$ AP-HP, Department of Pathology, Centre Hospitalier Intercommunal de Créteil, 94010 Créteil, France, ${ }^{10}$ AP-HP, Department of Pediatrics, \\ Groupe Hospitalier Necker-Enfants Malades, 75015 Paris, France, ${ }^{11}$ Laboratory of Molecular Genetics, Pharmacogenetics, Hormonology, Hôspital \\ Bicêtre, 94275 Le Kremlin-Bicêtre, France, ${ }^{12}$ INSERM U 693, Faculté de Médecine Paris Sud 11, 94275 Le Kremlin-Bicêtre, France, ${ }^{13}$ INSERM \\ U 854, Université Paris Sud XI, 94275 Le Kremlin-Bicêtre, France
}

(Correspondence should be addressed to P Touraine who is now at Department of Endocrinology and Reproductive Medicine, Groupe Hospitalier Pitié-Salpétrière, 75651 Paris Cedex 13, France; Email: philippe.touraine@psl.aphp.fr)

\begin{abstract}
Objective: Premature ovarian failure (POF) encompasses a heterogeneous spectrum of conditions, with phenotypic variability among patients. The etiology of POF remains unknown in most cases. We performed a global phenotyping of POF women with the aim of better orienting attempts at an etiological diagnosis.

Design and methods: We performed a mixed retrospective and prospective study of clinical, biological, histological, morphological, and genetic data relating to 357 consecutive POF patients between 1997 and 2008. The study was conducted at a reproductive endocrinology referral center.

Results: Seventy-six percent of the patients presented with normal puberty and secondary amenorrhea. Family history was present in 14\% of the patients, clinical and/or biological autoimmunity in $14.3 \%$. Fifty-six women had a fluctuating form of POF. The presence of follicles was suggested at ultrasonography in $50 \%$ of the patients, and observed in $29 \%$ at histology; the negative predictive value of the presence of follicles at ultrasonography was $77 \%$. Bone mineral density alterations were found in $58 \%$ of the women. Eight patients had X chromosomal abnormalities other than Turner's syndrome, eight other patients evidenced FMR1 pre-mutation. Two other patients had autoimmune polyendocrine syndrome type 2 and 1 .

Conclusion: A genetic cause of POF was identified in 25 patients, i.e. $7 \%$ of the whole cohort. POF etiology remains most often undiscovered. Novel strategies of POF phenotyping are in such content mandatory to improve the rate of POF patients for whom etiology is identified.
\end{abstract}

European Journal of Endocrinology 161 179-187

\section{Introduction}

Premature ovarian failure (POF) is a disorder associated with female infertility, which affects $\sim 1 \%$ of women under 40 years of age $(1,2)$. The diagnosis is supported by biochemical findings showing an association of elevated gonadotropins (FSH value $>30 \mathrm{U} / \mathrm{l}$ ) and a low estrogen level (1). In the absence of surgical oophorectomy, chemotherapy, and pelvic radiation, POF encompasses a heterogeneous spectrum of conditions, through two major mechanisms, follicle dysfunction and follicle depletion (3). Although causes such as autoimmunity, monosomy $\mathrm{X}$, and environmental factors play a role in primary ovarian insufficiency, the cause of the majority of cases remains unknown $(4,5)$. A genetic component has been suggested in POF pathophysiology, especially when the condition is associated with chromosomal abnormalities or when familial forms are found (6). Nevertheless, the identification of genetic causes of ovarian insufficiency has proved to be elusive. Syndromic POF has been demonstrated to be associated with some mutations 
(FOXL2, EIF2B, and GALT genes) (3). In non-syndromic forms, rare mutations in the FSH have been described, (1, 7-9), and our group has previously identified homozygous or compound heterozygous mutations of the FSHR gene in three POF patients (10-12). Some variants of other genes, such as BMP15, GDF9, and NOBOX and more recently some mutations of NR5A1 have also been reported (13-18). Nevertheless, mutations affecting all of these genes account for a small minority of all cases of ovarian dysfunction, which suggest that there are additional factors that remain to be identified.

This led us to set up a French network on POF for the purpose of better characterizing POF patients and understanding the mechanisms involved in this pathology. The objective of the present study was to report on our experience evaluating over 360 consecutive women referred to our national center with a diagnosis of POF. From these data, we documented the clinical and hormonal phenotype and the histological and morphological characteristics of the ovaries of these women and performed various genetic studies.

\section{Materials and methods}

\section{Study design}

The study was approved by the board of the different institutions involved and an informed consent was obtained from all the patients. Three hundred and ninety eight patients presenting with amenorrhea and elevated FSH levels were referred to our center between January 1997 and November 2008 with suspected POF, including 37 women referred before 1997. These patients were studied retrospectively before 2001 and thereafter prospectively. Spontaneous POF was defined by at least 4 months of amenorrhea, two FSH levels measured above $30 \mathrm{mIU} / \mathrm{ml}$ at an interval of at least 1 month, and a karyotype excluding Turner's syndrome. Women aged over 40 years at the time of diagnosis $(n=4)$, women with amenorrhea but with FSH levels between 20 and $30 \mathrm{mIU} / \mathrm{ml}(n=21)$, women with Turner's syndrome or Turner-like karyotype abnormalities $(n=6)$, patients with $46 \mathrm{XY}$ gonadal dysgenesis $(n=2)$ and women with a history of chemotherapy and/or pelvic radiotherapy $(n=8)$ were excluded. Three hundred and fifty seven patients met all the criteria and completed the study, which involved: i) gathering the clinical data available: age at diagnosis, clinical presentation, family history of POF, defined as an early menopause ( $\leq 40$ years of age) in a first-degree relative, personal, and family history of autoimmunity; ii) hormonal evaluation, including the measurement of $\mathrm{FSH}$, LH, estradiol $\left(\mathrm{E}_{2}\right)$, testosterone $(\mathrm{T})$, androstenedione (A), DHEA-S, inhibin B (from 1997), and AMH (from 2003) levels; iii) systematic screening for thyroid and ovarian autoimmunity and, after 2000, adrenal autoimmunity; iv) pelvic ultrasonography; v) ovarian biopsy for the evaluation of the ovarian reserve in patients who agreed to this procedure; vi) bone mineral density assessment (BMD); vii) DNA extraction for FMR1 gene analysis.

All the patients who underwent an ovarian biopsy and/or DNA analysis had given their specific informed consent in writing.

\section{Hormone measurements}

Plasma levels of FSH and LH were measured by conventional RIA (Immunotech Beckman, Marseille, France). $\mathrm{E}_{2}$ levels were determined after previous plasma extraction (DiaSorin, Milan, Italy, Schering CisBio International, Gif-sur-Yvette, France). The normal range was based on hormonal results obtained in healthy women during a normal menstrual cycle and provided by the laboratory of hormonal investigations at Necker Hospital. The intra-assay coefficient varied from 2.6 to $8.1 \%$ whereas the inter-assay coefficient varied from 3.7 to $11.9 \%$. The sensitivity of the $E_{2}$ assay was $10 \mathrm{pg} / \mathrm{ml}$. Inhibin B was measured in serum by an enzyme immunometric assay using Oxford Bio-Innovation reagents (Serotec, Oxford, UK) with a detection limit of $10 \mathrm{pg} / \mathrm{ml}$ and intra- and inter-assay coefficients of variation (CV) of 6 and $12 \%$, respectively. Inhibin $B$ level was considered to be $5 \mathrm{ng} / \mathrm{ml}$ when the level was $<10 \mathrm{ng} / \mathrm{ml}$. Serum AMH (AMH/MIS Elisa Immunotech, Beckman-Coulter) concentrations in serum samples were measured in duplicate using a sandwich ELISA method. The range of the assay was $0.4-21 \mathrm{ng} / \mathrm{ml}$. The intra- and inter-assay coefficients for AMH determination were 5.3 and $8.7 \%$ respectively. The normal range in women with normal menstrual cycles for days $3-5$ of the cycle is $2.2-6.8 \mathrm{ng} / \mathrm{ml}$ (19).

\section{Screening for autoimmunity}

Screening for adrenal autoimmunity was systematically performed beginning in 2000. Anti-adrenal antibodies were tested for by indirect immunofluorescence assay (Biorad); anti-21-hydroxylase antibodies were tested for beginning in 2004 by RIA (Cisbio Bioassays, Bagnols/ Ceze, France). Anti-ovarian antibodies were tested for by an indirect immunofluorescence test system supplied by Biorad, binding site. The kit includes frozen sections of cynomologous monkey ovary as a tissue substrate. Anti-thyroid antibodies (anti-thyroperoxydase (TPO) and anti-thyroglobulin (TG) antibodies) were tested for by passive hemagglutination assays and more recently by RIA.

\section{Pelvic ultrasonography}

Pelvic ultrasonography was performed using a Siemens Sonoline Elegra sonograph and a $6.5 \mathrm{MHz}$ probe. When 
available, the surface area of the ovaries was calculated as: $\mathrm{S}=\mathrm{L}$ (length) $\times \mathrm{W}$ (width) $\times 0.8$. The normal surface area of the ovary ranges between 2 and $6 \mathrm{~cm}^{2}(20)$.

\section{Morphological analysis of ovarian biopsies from POF patients}

For each patient who underwent ovarian biopsies by laparoscopy after informed consent, two biopsies measuring 3-5 mm, one from each ovary, were sampled and fixed in neutral formalin. After embedding in paraffin, the samples were serially sectioned at $5 \mu \mathrm{m}$, and then stained with hematoxylin/eosin/safran. One out of every 20 sections was examined and the number of resting and growing follicles was counted. The sections were carefully scrutinized in order to detect fragments of large follicles that might be present on the edges of the biopsy, as well as follicles in the ultimate stages of atresia and degenerated corpora lutea.

\section{BMD assessment}

Femoral neck and lumbar spine BMD were assessed by the same operator using a Hologic Densitometer QDR 1000. The daily quality control showed a $0.52 \%$ $\mathrm{CV}$ during the performance of these tests. BMD results at the femoral neck and lumbar spine $\left(\mathrm{L}_{2}-\mathrm{L}_{4}\right)$ were evaluated and expressed as absolute values in $\mathrm{g} / \mathrm{cm}^{2}$ and $T$-scores ((BMD-peak bone mass)/s.D). OFELY Caucasian reference curves were used to calculate the women's T-scores (21). We were able to use T-scores to interpret and compare the results, since all our patients were under the age of 40 and the general population's peak bone mass does not decrease at that age. In accordance with World Health Organization criteria, osteoporosis was defined as a T-score $<-2.5$ S.D. and osteopenia was defined as a T-score between -2.5 and -1 s.D. Normal bone has a BMD T-score of -1 s.D. or higher (22).

\section{Genotyping}

Genomic DNA was extracted from peripheral blood leukocytes. The total coding region of the human FSHR gene and adjacent intron-exon junctions were sequenced as previously described (7-9). Genomic sequencing was performed using a Taq di-deoxyterminator cycle sequencing kit and a 3130 automated sequencer (PE Applied Biosystems, Foster City, CA, USA). For FMR 1 testing, the region encompassing the CGG triplets was amplified by PCR in the presence of a fluorescent primer and the PCR product loaded onto the 3130 automated sequencer. The triplet size was evaluated using Genescan analysis software (PE Applied Biosystems). If the patient presented only one allele, a southern blot experiment was performed as previously described in order to diagnose a full mutation (23).

\section{Statistical analysis}

The analyses were processed by means of Statview, version 4.5 (Abacus Concepts, Berkeley, USA). Descriptive statistics were performed for each variable; quantitative results are presented as median (range); qualitative results are presented as a distribution of a number of patients. Hormonal and ovarian parameters were compared using the Mann-Whitney test. Proportions for the two groups were compared using the $\chi^{2}$-test. The agreement between histology and ultrasonography was analyzed by means of the $\kappa$-test. Characteristics of patients with reduced BMD versus patients with normal BMD were compared using the $\chi$-test for categorical variables or unpaired $t$-test for continuous variables. A study was performed in all patients and after exclusion of patients with X chromosome anomalies. Logistic regression model was used to determine factors independently associated to reduce BMD. $P<0.05$ was accepted as significant.

\section{Results}

\section{Clinical characteristics of the population}

Three hundred and fifty seven POF patients completed the study. Mean age was $26.5 \pm 7.8$ years $(11-39)$ at the time of the diagnosis and years (12-45) $28.7 \pm 7.9$ years at the time of the evaluation. Figure $1 \mathrm{~A}$ and $\mathrm{B}$ show the baseline demographic and clinical characteristics of these patients at diagnosis. Most of our patients $(n=272 ; 76 \%)$ presented with normal puberty and secondary amenorrhea, $42(11.7 \%)$ presented with primary amenorrhea and partial or normal pubertal development, and only 35 (9.8\%) displayed primary amenorrhea and pubertal delay.
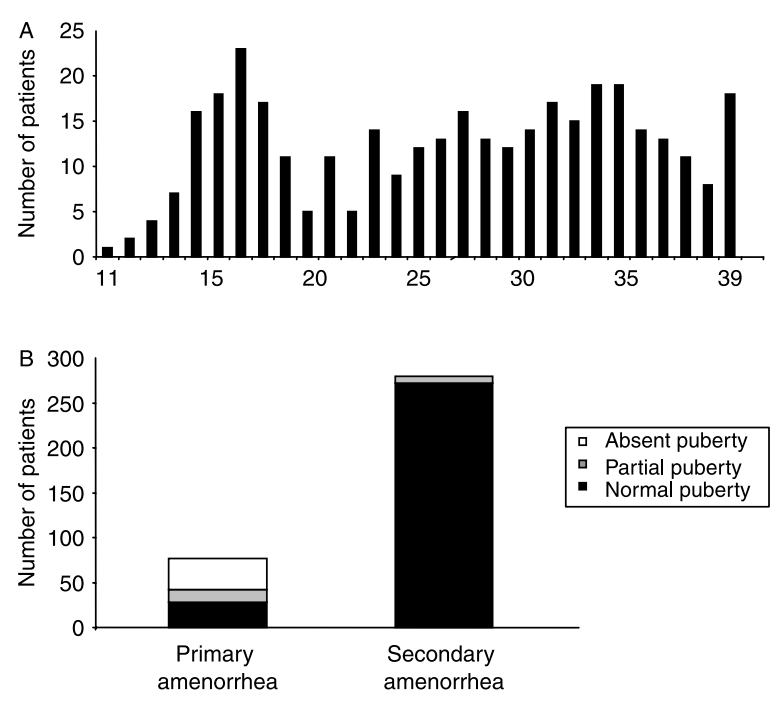

Figure 1 Clinical presentation of POF patients. A, distribution of age at diagnosis; B, type of amenorrhea and pubertal development at diagnosis. 
Forty-eight patients (14\%) had a family history of POF, whether this involved their mother (15 patients), one or more sisters (24 patients), mother and sister (three patients), mother and other relative, e.g. maternal grandmother and/or maternal aunt (six patients). The mean age at diagnosis was $26.0 \pm 8.0$ years, and $28.1 \pm 8.8$ years at the time of evaluation. Ten of the POF patients with a family history presented with primary amenorrhea. Four pairs of sisters (four families) were followed up and completed the entire evaluation within the framework of this study.

Fifty-five women (15.7\%) had a fluctuating form of POF, i.e. they had experienced spontaneous but temporary resumption of their menstrual cycles and/or normalization of their FSH levels in the course and/or experienced spontaneous pregnancy of their past history of POF (that is, prior to the evaluation). Most (54/55) of these patients presented with secondary amenorrhea, seven with a familial history of POF.

\section{Hormonal evaluation}

The median FSH level was 78.0 IU/l (30.3-284; normal range $(n), 3-9 \mathrm{IU} / \mathrm{l})$ and the median $\mathrm{LH}$ was $31.3 \mathrm{IU} / \mathrm{l}$ (5.9-109; $n: 1-5 \mathrm{IU} / \mathrm{l})$. The median $\mathrm{E}_{2}$ level was $10 \mathrm{pg} / \mathrm{ml}(<10-880) ; 163$ women had detectable levels (45\%). Twelve patients had LH levels higher than their FSH levels. These 12 patients presented with secondary amenorrhea and normal puberty. Inhibin B values were available for 254 patients; the median level was $5 \mathrm{pg} / \mathrm{ml}$ (5-381; $n$ : 60-200 ng/l). Ninety-seven women $(38 \%)$ had detectable levels. Serum AMH concentration was available for 147 patients. Serum AMH was below the detection threshold $(0.4 \mathrm{ng} / \mathrm{ml})$ in 113 women $(77 \%)$, below the normal range in 27 women $(18 \%)$ and within the normal range in seven women $(5 \%)$. Serum AMH values were negatively correlated with the age of the patients $(r=-0.23$, $P=0.005)$. Serum $E_{2}$ correlated with inhibin B levels $(r=0.43, P<0.001)$. No correlation, either positive or negative, was found between $\mathrm{AMH}$, inhibin $\mathrm{B}$, and $\mathrm{FSH}$. No significant difference was observed between FSH, inhibin B, and AMH levels of patients presenting with either primary or secondary amenorrhea (Fig. 2). However, $\mathrm{E}_{2}$ levels were higher in women with secondary amenorrhea than in patients with primary amenorrhea $(29.6 \pm 63.5$ vs $12.8 \pm 11.5 \mathrm{pg} / \mathrm{ml}$, $P=0.006$; Fig. 2).

\section{Autoimmunity}

Thirty-six patients (10.1\% of the whole cohort) presented with a personal history of one or more autoimmune diseases other than adrenal insufficiency; most of them suffered from Hashimoto's thyroiditis (21) or Graves' disease (8). Seven had other autoimmune diseases, such as systemic lupus erythematosus, vitiligo, or polyarthritis. One of these five patients presented with
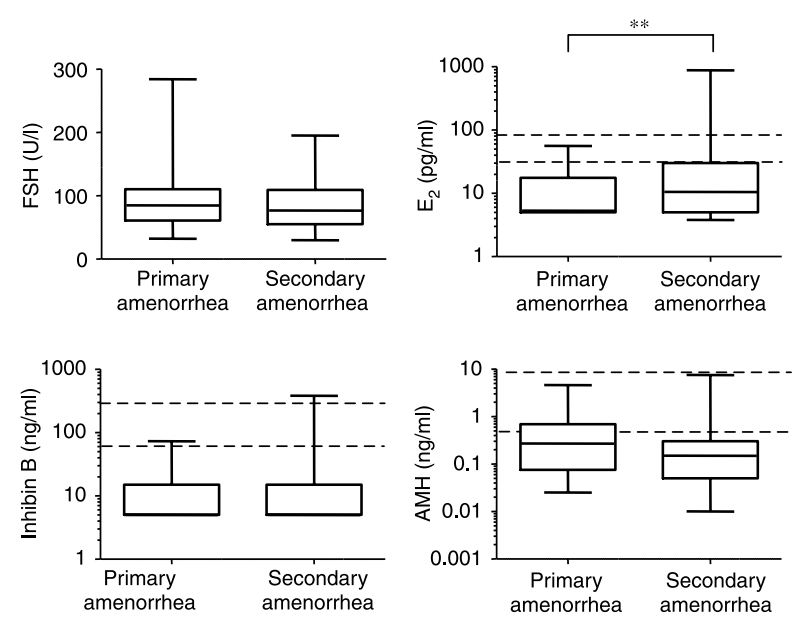

Figure 2 FSH, estradiol, inhibin $\mathrm{B}$, and $\mathrm{AMH}$ levels (log scale) in POF patients presented with primary amenorrhea or secondary amenorrhea. Normal reference values are represented between the two dotted lines. ${ }^{\star \star} P<0.01$.

an association of glomerulonephritis, idiopathic thrombocytopenic purpura, myasthenia, and POF.

Seven patients $(2.3 \%$ of the 298 patients tested for ovarian autoimmunity) tested positive for ovarian antibody. Three patients $(1.2 \%$ of the 249 patients biologically tested for adrenal autoimmunity) had antiadrenal autoimmunity. Two presented with APS type 2 (adrenal insufficiency, Hashimoto's thyroiditis, and POF; adrenal insufficiency, type 1 diabetes, and POF) and also tested positive for ovarian auto-antibodies. One presented with isolated anti-adrenal antibodies without biological adrenal insufficiency. Isolated anti-ovarian antibodies were found among four patients. One of them had a family history of POF involving a sister. None of these patients had undergone an ovarian biopsy at the time of diagnosis.

Antithyroglobulin and/or antiTPO antibodies without thyroid dysfunction were found in 20 patients. Overall, 44 women (14.8\% of the 297 patients tested for thyroid autoimmunity) had positive anti-thyroglobulin and/or anti-TPO antibodies, with or without thyroid dysfunction. The mean and median levels of LH and inhibin B were not significantly different in women with autoimmunity and women in whom it was absent.

\section{Pelvic ultrasonography}

Three hundred and twenty one patients underwent pelvic ultrasonography. Ovaries were not found in 12 patients. Only one ovary was found at ultrasonography in 13 patients. The surface area of the ovaries could be calculated in 234 patients. The median surface area was $1.59 \mathrm{~cm}^{2}(0.28-15.3)$. The ovaries were considered to have either a normal surface area $\left(\geq 2 \mathrm{~cm}^{2}\right)$, as was the case in 94 patients $(38 \%)$, or a small surface area $\left(<2 \mathrm{~cm}^{2}\right)$, as was the case in the 

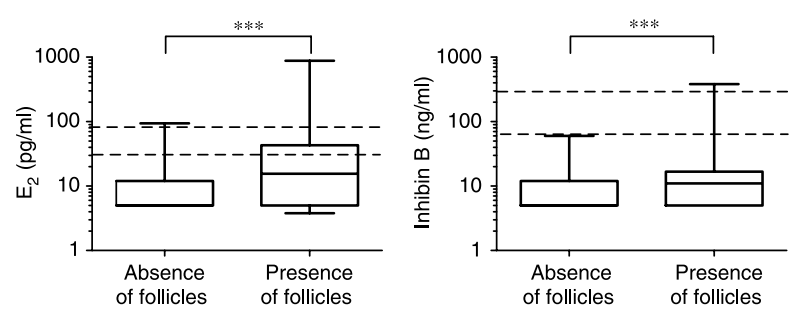

Figure 3 Estradiol and inhibin B levels (log scale) in POF patients with or without follicles at ultrasonography. Normal reference values are represented between the two dotted lines. ${ }^{\star \star \star} P<0.001$.

remaining 140 (62\%). Images suggesting the presence of follicles with a diameter $\geq 2 \mathrm{~mm}$ were observed in $50 \%$ of the patients. This clearly correlates with the size of the ovaries $(P=0.008)$, since images of follicles were observed in 67 of the 87 patients whose ovaries had a normal surface area $(77 \%)$. The patients in whom follicles were seen at ultrasonography presented mostly with secondary amenorrhea (87\%) and were older than those in whom none were observed $(30.5 \pm 7.4$ vs $27.8 \pm 7.8$ years, $P<0.004)$. Inhibin B and $E_{2}$ levels were higher in patients in whom follicles were observed $(17.9 \pm 38.5$ vs $8.4 \pm 7.1 \mathrm{pg} / \mathrm{ml}$, $P<0.001$, and $33.8 \pm 42.4$ vs $12.6 \pm 14.1 \mathrm{pg} / \mathrm{ml}$, $P<0.001$, respectively; Fig. 3).

\section{Ovarian histology}

One hundred and eleven patients underwent ovarian biopsies per laparoscopy. Follicles, either non-growing or with evidence of follicular growth (i.e. presence of follicles at various stages of maturation/involution), were observed in the ovaries of 33 patients $(29 \%)$. A follicular reserve with primordial follicles was detected in 17 cases and primary follicles in six cases. Follicular growth as evidenced by the presence of secondary follicles was observed in four cases, early antral follicles in three cases and antral follicles in one case. No specimens showed any autoimmune lymphocytic infiltrate.

Follicles were absent in the ovaries of 79 patients (71\%). Age, $\mathrm{E}_{2}, \mathrm{AMH}$, inhibin B, FSH, and $\mathrm{LH}$ levels were compared in patients with histological evidence of follicles and those without follicles. No difference was observed between the two groups, and the overlap between them appears to be considerable.

\section{Bone mineral density}

Osteodensitometry data were available for 189 patient but results concern 183 patients with normal karyotype. The median (range) age of these women at the time of diagnosis was 28.0 (15-39) years. The median (range) time since the diagnosis of POF was 2 (0.5-36) years. One hundred and seventeen (64\%) women had sought medical advice previously and had taken a variety of estrogen and progestin replacement regimens at least intermittently. According to the WHO definition, 78 patients $(42.7 \%)$ had normal BMD; osteopenia was found in 80 patients $(43.7 \%$ ), including 21 at femoral neck, 29 in the lumbar spine, and 30 at both sites; osteoporosis was found in 25 patients (13.7\%), including two at the femoral neck, 18 in the lumbar spine, and five at both sites. In univariate analysis, factors significantly associated with a reduced BMD were a lower body mass index (BMI; $P=0.0002)$, primary amenorrhea $(P=0.0011)$, duration of POF $(P=0.0056)$, and age at diagnosis $(P=0.0045)$, whereas treatment and smoking were not. In multivariate logistic regression analysis, primary amenorrhea $(\mathrm{OR}=3.6, \quad(1.09-11.82), \quad P=0.04)$, BMI $(P=0.036)$, and POF duration $(P=0.044)$ remained significantly associated with a reduced BMD. Results were similar if all patients were included in the analysis.

\section{Karyotype abnormalities}

Eight patients $(2.2 \%)$ were found to have a karyotype abnormality located on the $\mathrm{X}$ chromosome (other than Turner's syndrome), which may explain their POF $(24,25)$. The height of all these patients was normal (1.53-1.83 m). The karyotype abnormalities consisted of chromosome X deletions $(n=4)$, chromosome X translocations $(n=2)$, and other chromosome $\mathrm{X}$ abnormalities in two patients (centromeric duplication of the $\mathrm{X}$ chromosome and $46 \mathrm{X} \operatorname{der}(\mathrm{X}) \mathrm{t}(\mathrm{X} ; \mathrm{Y})$ (q?28;q?11.2). Six other patients had autosomal abnormalities unrelated to POF. Among these eight patients, six had BMD measurement: two had normal BMD, two had osteopenia, and the remaining two patients had osteoporosis.

\section{Genetic analysis}

Sequencing of the complete coding region of the human FSHR gene was performed in 159 patients, including all patients in whom ovarian biopsy revealed the presence of follicles. This analysis was negative, except in the three women already described (10-12). These women did not appear to be phenotypically different from the other POF patients.

The evaluation of the CGG number at the FMR1 locus was performed in 197 patients. Eight patients (4.0\%) presented a pre-mutation. None of these patients had a known family history of POF or a family history of mental retardation. Two of these patients presented a fluctuating form of POF. All of them presented with secondary amenorrhea, and five of them showed follicles at ultrasonography. Three pre-mutated patients underwent ovarian biopsy, which evidenced the presence of primordial follicles in two cases and no follicle in the remaining patient. No full mutation was found. 


\section{Discussion}

The prevalence and natural history of the clinical and biological manifestations of POF remain poorly characterized, and there have been few previous large-scale studies of the characteristics of this condition $(4,5,26)$. The present study reports clinical, biological, histological, ultrasonographic, and genetic data collected in a cohort of 357 women with POF, the largest one described to date. We were able to identify the etiology of POF in 28 patients $(7.8 \%$, Table 1$)$ : eight with chromosomal abnormalities other than Turner's syndrome, eight with FMR1 pre-mutation, eight with molecular alterations in candidate genes possibly or certainly associated with POF (FSHR, GDF9, BMP15, or meiosis gene) $(10-12,14,27)$, one with congenital disorders of glycosylation syndrome, two with APS type 2 and one with multiple autoimmune diseases. POF remains idiopathic in the other cases.

The clinical presentation of our POF patients was variable. Most of them presented with secondary amenorrhea, which is less frequently associated with an abnormal karyotype than primary amenorrhea (25). The young age of this cohort may be related in part to referral bias, as many patients were referred by pediatric healthcare facilities. We previously described 63 patients of this cohort who presented with early onset of POF (28), which might have been a more homogenous population. Nevertheless, while the FSHR mutations were found in this population, the etiology of POF was not identified in a majority of cases. Furthermore, the present data show that other identified genetic causes of POF, i.e. X chromosome abnormalities and FMR 1 premutations, may be found in POF patients with secondary amenorrhea and adult onset, suggesting that the search for etiology does not rely on clinical presentation. However, this does not exclude the interest in searching other clinical POF cases within the family or relatives who presented early menopause, between 40 and 45 years. Indeed, some studies suggest that POF and early menopause show the same genetic features and that these conditions may be a variable expression of the same genetic disease (29, 30).

Our study shows also that over $58 \%$ of POF patients experienced BMD alteration, highlighting the importance of estrogen therapy. The risk of reduced BMD is significantly associated with the duration of POF. Women with primary amenorrhea seem to be particularly at risk. We suggest that hormone replacement therapy should be begun early and pursued consistently in POF patients.

Hormonal evaluation is also of value in these patients. Despite the problem of missing data, our cohort is large enough to give power to our results. We had previously studied ovarian steroidogenesis and androgen levels in our patients (31), and this study confirmed our former results, as we found $14 \%$ of
Table 1 Etiology of premature ovarian failure in 28 patients.

\begin{tabular}{lcl}
\hline Etiology & $\begin{array}{c}\text { Number of } \\
\text { patients }\end{array}$ & References \\
\hline $\begin{array}{l}\text { Homozygous or compound } \\
\text { heterozygous mutation of }\end{array}$ & 3 & $(10)$ \\
FSHR & & $(12)$ \\
& & \\
BMP15 variant & 3 & $(14)$ \\
DMC1 homozygote mutation & 1 & $(27)$ \\
Heterozygous substitution in & 1 & $(27)$ \\
exon 2 of $M S H 5$ & & \\
CDG syndrome & 1 & \\
Chromosomal abnormalities & 8 & \\
other than Turner syndrome & & \\
FMR1 premutation & & \\
58 CGG repeats & 1 & \\
79 CGG repeats & 1 & \\
80 CGG repeats & 1 & \\
85 CGG repeats & 1 & \\
86 CGG repeats & 1 & \\
89 CGG repeats & 1 & \\
93 CGG repeats & 1 & \\
99 CGG repeats & 1 & \\
Ovarian autoimmunity & 3 & \\
Total & 28 & \\
\hline
\end{tabular}

patients with detectable levels in this cohort (data not shown). Indeed, POF was not systematically associated with androgen deficiency, as had been described (32). Another important problem in POF is the assessment of the presence of follicles (33). This may lead to a distinction between two different situations: the absence of follicles is likely to be due to a molecular defect of the genes involved in oogenesis, the formation of the ovarian reserve or apoptosis, while the presence of follicles whose maturation has been blocked is due to defects of the genes involved in follicular growth (34). Plasma levels of $E_{2}$, inhibin $\mathrm{B}$, and $\mathrm{AMH}$ are of limited value in predicting the presence of an ovarian reserve in patients with POF (20), but in the present study $\mathrm{E}_{2}$ and inhibin B correlated well with the presence of follicles at ultrasonography. We previously demonstrated that AMH levels in POF patients could identify women with persistent small follicles (35), but the value of serum AMH monitoring in POF has to be further evaluated in prospective studies. Unlike other authors $(36,37)$, we concluded, on the basis of our previous and current studies, that ovarian histology appears to be a more reliable tool in evaluating the follicular reserve (20). Indeed, the comparison of follicular pattern at pelvic ultrasonography and at ovarian biopsy confirms our previous data (20). In 47 patients, images suggesting the presence of follicles were observed at ultrasonography. Follicles were observed at histology in only 19 of these, whereas they were absent in 28 of them. In 52 patients, no follicle was found at ultrasonography. Forty of these did in fact lack follicles at histology, whereas follicles were present in the ovaries of twelve of them. Ultrasonography appears then to be a 
poor marker when it comes to predicting the presence of resting follicles at ovarian histology, but demonstrates a good negative predictive value $(80 \%)$. However, it appears clearly that ovarian biopsy, since it is an invasive procedure and has no impact on the care of these patients, is not indicated routinely and should be performed only in selected cases in the context of clinical research. We thought that it would be interesting to carry out prospective studies of the subgroup of women with detectable $\mathrm{E}_{2}$, inhibin $\mathrm{B}$, and AMH levels, together with the presence of follicles at ultrasonography, in order to determine whether these patients present some menstruations or spontaneous pregnancies and whether these patients are good candidates for genetic studies of genes involved in folliculogenesis.

In our strategy, the search for POF aetiology was based on the screening of autoimmunity, karyotype, FMR1 premutation, and FHSR gene mutation in patients with follicles. The association between POF and numerous organ-specific autoimmune diseases has been documented for many years. Its prevalence has been evaluated variously, from $10-20$ to $55 \%$ (2). The diagnosis of autoimmune mechanisms in POF is difficult and remains controversial; the search for anti-ovarian antibodies relies on indirect immunofluorescence and seems to have low specificity. Adrenal autoimmunity is rare, but is the best-known association with POF (38). Moreover, some authors have found a clear association between the presence of adrenal cortex auto-antibodies and histologically confirmed autoimmune oophoritis $(39,40)$. In our cohort, two of the three patients with adrenal autoimmunity also evidenced ovarian autoimmunity, while only four of the 298 remaining patients did. Prevalence of anti-adrenal autoimmunity is quite low in our cohort, as compared to others (26), but may have been underestimated, as specific screening for 21-hydroxylase antibodies by RIA was performed only recently. Other known autoimmune diseases were present in less than $10 \%$ of the cohort. Thyroid autoimmune diseases were the most frequent, but did not appear to be significantly more frequent than in the general population (41).

The prevalence of FMR1 premutation in our cohort $(4.0 \%)$ was similar to that already reported in the literature, i.e. reported to occur $0.8-7.5 \%$ of sporadic presentations (42-44). When karyotype analysis, the search for FMR1 premutation and autoimmune disease remain negative, a search for mutations of $\mathrm{POF}$ candidate genes must be scheduled, taking into account the phenotypic characteristics of the patients, especially the presence or absence of follicles. Our strategy included also FSHR mutation screening among patients with an ultrasonographic and/or histological follicular reserve. This enabled us to identify only three patients with FSHR mutations on both alleles, previously described (10-12), among the 159 patients tested $(1.8 \%)$. Six patients with nine different loss-of-function mutations of the FSHR have been identified worldwide (7, 7-12, 45). They presented with different phenotypes (primary or secondary amenorrhea, familial or sporadic cases), but only a few descriptions note the presence of an ovarian phenotype.

More and more genes involved in normal follicular and ovarian development are being identified, based on the data obtained from animal models (46), and correspond to candidate genes in this syndrome. Among these, GDF9 and BMP15 and more recently meiosis genes have become candidate genes for POF (13-15, 27). However, they demonstrate variable clinical expressions, and their clinical relevance is not clear. Moreover, we demonstrated that despite the potential for $\mathrm{FOXO} 3$ haploinsufficiency to cause ovarian failure, FOXO3 mutations were not a common cause of either POF (47). Other genes may be potentially involved in POF in women, according to animal models, as NOBOX, connexin 37, $\beta F S H(17,48,49)$. However, their position in the genetic diagnosis strategy is actually not clear.

Genotyping of POF patients could then in the near future increase the rate of POF patients for whom etiology is identified. Two approaches are then conceivable: the first one is a systematic sequencing of the known genes involved in POF in the whole cohort, determining the prevalence of these defects in the population; we performed this strategy for FSHR gene and it could be applied to patients who evidence follicles at ultrasonography or who present with POF familial forms. The second strategy should consist of sequencing first a subgroup of patients based on the ovarian phenotype of mouse models. This should be discussed, since no clear genotype-phenotype correlation appears to date and since animal models are not always relevant to human physiology. The candidate gene strategy is expected to be relevant to detecting, in the near future, women who are at risk for such a syndrome and to proposing new therapeutic approaches, from ovarian cryopreservation to in vitro follicular maturation.

\section{Declaration of interest}

The authors declare that there is no conflict of interest that could be perceived as prejudicing the impartiality of the research reported.

\section{Funding}

This study was supported by a grant from INSERM and GIS Institut des maladies rares, as well as by the financial aid and insurance contributed by the DRC-Ile de France.

\section{Acknowledgements}

We thank Yvette Le Rouzic, Valérie Michaud, Nicole Delamare, Fabienne Dufernez, Jérome Bouliguand, Sarah Maillet, and Martine Mathion for their technical assistance. POF-GIS (Premature Ovarian Failure-Groupement d'Intérêt Scientifique) study group: Martine Arnoux, Nicole Athéa, Juliane Berdah, Anne-Marie Bertrand, Bettina Bständig, Claire Bricaire, Dominique Buschsenschutz, Jean-Claude 
Carel, Olivier Chabre, Philippe Chanson, Carine Courtillot, Hélène Crosnier, Brigitte Delemer, Catherine Deneux, Mirabelle Detoeuf, Anne Dib, Catherine Duflos, Brigitte Emperauger, Patrick Fénichel, Olivia Fiori, Marie-Béatrice Galand-Portier, Julie Galey, Catherine Génestie, Alain Gougeon, Anne Grimard, Anne-Marie Guedj, Anne-Claude Hécart, Thierry Husson, Boris Keren, Sandrine Kretz, Pierre Lecomte, Isabelle Leroux, Hélène Letur, Myriam Lungo, Jacqueline Mandelbaum, Laurence Meng, Chantal Metz, Brigitte Mignot, Iab Nakib, Caroline Pichard, Geneviève Plu-Bureau, Michel Polak, Marguerite Prieur, Michel Pugeat, Brigitte Raccah-Tebeka, Catherine RaynaudRavni, Jean-Christophe Thalabard, Hélène Bony-Trifunovic, MarieCécile Vacher-Lavenu, Joëlle Viriot, Jean-René Zorn.

\section{References}

1 Beck-Peccoz P \& Persani L. Premature ovarian failure. Orphanet Journal of Rare Diseases 20061 9-14.

2 Goswami D \& Conway GS. Premature ovarian failure. Hormone Research 200768 196-202.

3 Nelson LM. Clinical practice. Primary ovarian insufficiency. New England Journal of Medicine 2009360 606-614.

4 Kim TJ, Anasti JN, Flack MR, Kimzey LM, Defensor RA \& Nelson LM. Routine endocrine screening for patients with karyotypically normal spontaneous premature ovarian failure. Obstetrics and Gynecology 199789 777-779.

5 Rebar RW, Erickson GF \& Yen SS. Idiopathic premature ovarian failure: clinical and endocrine characteristics. Fertility and Sterility $19823735-41$.

6 Gosden RG, Treloar SA, Martin NG, Cherkas LF, Spector TD, Faddy MJ \& Silber SJ. Prevalence of premature ovarian failure in monozygotic and dizygotic twins. Human Reproduction 200722 610-615.

7 Aittomaki K, Lucena JL, Pakarinen P, Sistonen P, Tapanainen J, Gromoll J, Kaskikari R, Sankila EM, Lehvaslaiho H, Engel AR, Nieschlag E, Huhtaniemi I \& de la Chapelle A. Mutation in the follicle-stimulating hormone receptor gene causes hereditary hypergonadotropic ovarian failure. Cell 199582 959-968.

8 Doherty E, Pakarinen P, Tiitinen A, Kiilavuori A, Huhtaniemi I, Forrest S \& Aittomaki K. A novel mutation in the FSH receptor inhibiting signal transduction and causing primary ovarian failure. Journal of Clinical Endocrinology and Metabolism 200287 1151-1155.

9 Allen LA, Achermann JC, Pakarinen P, Kotlar TJ, Huhtaniemi IT, Jameson JL, Cheetham TD \& Ball SG. A novel loss of function mutation in exon 10 of the FSH receptor gene causing hypergonadotrophic hypogonadism: clinical and molecular characteristics. Human Reproduction 200318 251-256.

10 Beau I, Touraine P, Meduri G, Gougeon A, Desroches A, Matuchansky C, Milgrom E, Kuttenn F \& Misrahi M. A novel phenotype related to partial loss of function mutations of the follicle stimulating hormone receptor. Journal of Clinical Investigation $1998 \mathbf{1 0 2} 1352-1359$.

11 Touraine P, Beau I, Gougeon A, Meduri G, Desroches A, Pichard C, Detoeuf M, Paniel B, Prieur M, Zorn JR, Milgrom E, Kuttenn F \& Misrahi M. New natural inactivating mutations of the folliclestimulating hormone receptor: correlations between receptor function and phenotype. Molecular Endocrinology $1999 \quad 13$ 1844-1854.

12 Meduri G, Touraine P, Beau I, Lahuna O, Desroches A, Vacher-Lavenu MC, Kuttenn F \& Misrahi M. Delayed puberty and primary amenorrhea associated with a novel mutation of the human follicle-stimulating hormone receptor: clinical, histological, and molecular studies. Journal of Clinical Endocrinology and Metabolism $2003 \mathbf{8 8} 3491-3498$.

13 Di Pasquale E, Beck-Peccoz P \& Persani L. Hypergonadotropic ovarian failure associated with an inherited mutation of human bone morphogenetic protein-15 (BMP15) gene. American Journal of Human Genetics 200475 106-111.
14 Laissue P, Christin-Maitre S, Touraine P, Kuttenn F, Ritvos O, Aittomaki K, Bourcigaux $\mathrm{N}$, Jacquesson $\mathrm{L}$, Bouchard $\mathrm{P}$, Frydman R, Dewailly D, Reyss AC, Jeffery L, Bachelot A, Massin N, Fellous M \& Veitia RA. Mutations and sequence variants in GDF9 and BMP15 in patients with premature ovarian failure. European Journal of Endocrinology 2006154 739-744.

15 Di Pasquale E, Rossetti R, Marozzi A, Bodega B, Borgato S, Cavallo L, Einaudi S, Radetti G, Russo G, Sacco M, Wasniewska M, Cole T, Beck-Peccoz P, Nelson LM \& Persani L. Identification of new variants of human BMP15 gene in a large cohort of women with premature ovarian failure. Journal of Clinical Endocrinology and Metabolism 200691 1976-1979.

16 Lourenco D, Brauner R, Lin L, De Perdigo A, Weryha G, Muresan M, Boudjenah R, Guerra-Junior G, Maciel-Guerra AT, Achermann JC, McElreavey K \& Bashamboo A. Mutations in NR5A1 associated with ovarian insufficiency. New England Journal of Medicine 2009360 1200-1210.

17 Rajkovic A, Pangas SA, Ballow D, Suzumori N \& Matzuk MM. NOBOX deficiency disrupts early folliculogenesis and oocytespecific gene expression. Science 2004305 1157-1159.

18 Zhao XX, Suzumori N, Yamaguchi M \& Suzumori K. Mutational analysis of the homeobox region of the human NOBOX gene in Japanese women who exhibit premature ovarian failure. Fertility and Sterility 200583 1843-1844.

19 Pigny P, Merlen E, Robert Y, Cortet-Rudelli C, Decanter C, Jonard S \& Dewailly D. Elevated serum level of anti-mullerian hormone in patients with polycystic ovary syndrome: relationship to the ovarian follicle excess and to the follicular arrest. Journal of Clinical Endocrinology and Metabolism 200388 5957-5962.

20 Massin N, Gougeon A, Meduri G, Thibaud E, Laborde K, Matuchansky C, Constancis E, Vacher-Lavenu MC, Paniel B, Zorn JR, Misrahi M, Kuttenn F \& Touraine P. Significance of ovarian histology in the management of patients presenting a premature ovarian failure. Human Reproduction 200419 2555-2560.

21 Arlot ME, Sornay-Rendu E, Garnero P, Vey-Marty B \& Delmas PD. Apparent pre- and postmenopausal bone loss evaluated by DXA at different skeletal sites in women: the OFELY cohort. Journal of Bone and Mineral Research 199712 683-690.

22 Bates DW, Black DM \& Cummings SR. Clinical use of bone densitometry: clinical applications. Journal of the American Medical Association $2002 \mathbf{2 8 8} 1898-1900$.

23 Oberle I, Rousseau F, Heitz D, Kretz C, Devys D, Hanauer A, Boue J, Bertheas MF \& Mandel JL. Instability of a 550-base pair DNA segment and abnormal methylation in fragile X syndrome. Science 1991252 1097-1102.

24 Therman E, Laxova R \& Susman B. The critical region on the human Xq. Human Genetics 199085 455-461.

25 Schlessinger D, Herrera L, Crisponi L, Mumm S, Percesepe A, Pellegrini M, Pilia G \& Forabosco A. Genes and translocations involved in POF. American Journal of Medical Genetics 2002111 328-333.

26 Conway GS, Kaltsas G, Patel A, Davies MC \& Jacobs HS. Characterization of idiopathic premature ovarian failure. Fertility and Sterility $199665337-341$.

27 Mandon-Pepin B, Touraine P, Kuttenn F, Derbois C, Rouxel A, Matsuda F, Nicolas A, Cotinot C \& Fellous M. Genetic investigation of four meiotic genes in women with premature ovarian failure. European Journal of Endocrinology $2008 \mathbf{1 5 8} 107-115$.

28 Massin N, Czernichow C, Thibaud E, Kuttenn F, Polak M \& Touraine P. Idiopathic premature ovarian failure in 63 young women. Hormone Research 200665 89-95.

29 Kok HS, van Asselt KM, van der Schouw YT, Peeters PH \& Wijmenga C. Genetic studies to identify genes underlying menopausal age. Human Reproduction Update 200511 483-493.

30 Tibiletti MG, Testa G, Vegetti W, Alagna F, Taborelli M, Dalpra L, Bolis PF \& Crosignani PG. The idiopathic forms of premature menopause and early menopause show the same genetic pattern. Human Reproduction 199914 2731-2734. 
31 Bachelot A, Meduri G, Massin N, Misrahi M, Kuttenn F \& Touraine P. Ovarian steroidogenesis and serum androgen levels in patients with premature ovarian failure. Journal of Clinical Endocrinology and Metabolism $2005902391-2396$.

32 Kalantaridou SN, Calis KA, Vanderhoof VH, Bakalov VK, Corrigan EC, Troendle JF \& Nelson LM. Testosterone deficiency in young women with $46, \mathrm{XX}$ spontaneous premature ovarian failure. Fertility and Sterility $2006 \mathbf{8 6}$ 1475-1482.

33 Massin N, Meduri G, Bachelot A, Misrahi M, Kuttenn F \& Touraine P. Evaluation of different markers of the ovarian reserve in patients presenting with premature ovarian failure. Molecular Cell $2007 \mathbf{2 8 2}$ 95-100.

34 Anasti JN. Premature ovarian failure: an update. Fertility and Sterility 1998 70 $1-15$.

35 Meduri G, Massin N, Guibourdenche J, Bachelot A, Fiori O, Kuttenn F, Misrahi M \& Touraine P. Serum anti-Mullerian hormone expression in women with premature ovarian failure. Human Reproduction 200722 117-123.

36 Schmidt KL, Byskov AG, Nyboe AA, Muller J \& Yding AC. Density and distribution of primordial follicles in single pieces of cortex from 21 patients and in individual pieces of cortex from three entire human ovaries. Human Reproduction 200318 1158-1164.

37 Lass A. Assessment of ovarian reserve: is there still a role for ovarian biopsy in the light of new data? Human Reproduction 2004 19 467-469.

38 Bakalov VK, Vanderhoof VH, Bondy CA \& Nelson LM. Adrenal antibodies detect asymptomatic auto-immune adrenal insufficiency in young women with spontaneous premature ovarian failure. Human Reproduction 200217 2096-2100.

39 Bakalov VK, Anasti JN, Calis KA, Vanderhoof VH, Premkumar A, Chen S, Furmaniak J, Smith BR, Merino MJ \& Nelson LM. Autoimmune oophoritis as a mechanism of follicular dysfunction in women with 46,XX spontaneous premature ovarian failure. Fertility and Sterility $2005 \mathbf{8 4} 958-965$.

40 Tsigkou A, Marzotti S, Borges L, Brozzetti A, Reis F, Candeloro P, Bacosi ML, Bini V, Petraglia F \& Falorni A. High serum inhibin concentration discriminates autoimmune oophoritis from other forms of primary ovarian insufficiency. Journal of Clinical Endocrinology 200893 1263-1269.

41 O’Leary PC, Feddema PH, Michelangeli VP, Leedman PJ, Chew GT, Knuiman M, Kaye J \& Walsh JP. Investigations of thyroid hormones and antibodies based on a community health survey: the Busselton thyroid study. Clinical Endocrinology 2006 64 97-104.

42 Conway GS, Payne NN, Webb J, Murray A \& Jacobs PA. Fragile X premutation screening in women with premature ovarian failure. Human Reproduction 199813 1184-1187.

43 Wittenberger MD, Hagerman RJ, Sherman SL, McConkie-Rosell A, Welt CK, Rebar RW, Corrigan EC, Simpson JL \& Nelson LM. The FMR1 premutation and reproduction. Fertility and Sterility 2007 87 456-465.

44 Gersak K, Meden-Vrtovec H \& Peterlin B. Fragile X premutation in women with sporadic premature ovarian failure in Slovenia. Human Reproduction 2003 18 1637-1640.

45 Bridges RS, Dibiase R, Loundes DD \& Doherty PC. Prolactin stimulation of maternal behavior in female rats. Science $1985 \mathbf{2 2 7}$ 782-784.

46 Elvin JA \& Matzuk MM. Mouse models of ovarian failure. Reviews of Reproduction 19983 183-195.

47 Gallardo TD, John GB, Bradshaw K, Welt C, Reijo-Pera R, Vogt PH, Touraine P, Bione S, Toniolo D, Nelson LM, Zinn AR \& Castrillon DH. Sequence variation at the human FOXO3 locus: a study of premature ovarian failure and primary amenorrhea. Human Reproduction $200823216-221$.

48 Simon AM, Goodenough DA, Li E \& Paul DL. Female infertility in mice lacking connexin 37. Nature 1997385 525-529.

49 Kumar TR, Wang Y, Lu N \& Matzuk MM. Follicle stimulating hormone is required for ovarian follicle maturation but not male fertility. Nature Genetics 199715 201-204.

Received 16 April 2009

Accepted 20 April 2009 